\title{
Bakhtín e a Semiótica Musical Contemporânea
}

\author{
LUCIANO CAMARGO \\ UNIVERSIDADE FEDERAL DE RORAIMA(UFRR) \\ (luciano.camargo@ufrr.br)
}

PAULO DE TARSO SALLES

UNIVERSIDADE DE SAO PAULO(USP)

(ptsalles@usp.br)

\section{Introdução}

$\mathcal{F}^{\mathrm{m}}$ sua busca pela elaboração de uma teoria cultural ampla, que deveria englobar a teoria literária, Bakhtín abriu as portas para uma nova compreensão das artes, em conexão com o contexto sociocultural em que estão inseridas. No comentário sobre The Formal Method in Literary Scholarship, atribuído ${ }^{1}$ a Bakhtín e Medvedev, Beth Brait enfatiza:

(...) o interesse pelas características e formas do intercurso social pelo qual o significado é realizado: procura explorar a ideia e centrar a discussão no fato de que a linguagem não é falada no vazio, mas numa situação histórica e social concreta no momento e no lugar da atualização do enunciado. (BRAIT, 1997, p. 96)

Esse intercurso social é apresentado como o elemento que une a presença material da palavra com seu significado, em uma espécie de dialética do signo. Esta visão é apresentada de forma radical, quando Bakhtín afirma que:

A conexão entre significado e signo na palavra tomada de forma concreta e independente de sua enunciação, como no

\footnotetext{
${ }^{1}$ Não há consenso entre os estudiosos sobre a autoria deste livro, uma vez que não há documentação manuscrita original com esta informação. Há consenso, porém, de que o(s) autor(es) pertence(m) ao círculo de Bakhtín, o grupo de estudos ligado ao pensador. A informação editorial oficial atribui a autoria da obra a Pavel Nikolaevitch Medvedev e ao próprio Bakhtín, em conjunto.
} 
dicionário, é completamente aleatória e tem somente significância técnica. Aqui, a palavra é simplesmente um signo convencional. Existe uma distância entre a individualidade da palavra e seu significado, uma distância que só pode ser vencida por um encadeamento sistemático, uma associação (...) Toda elocução concreta é um ato social, faz parte de uma realidade social. (BAKHTíN; MEDVEDEV, 1991, p. 120).

Partindo destas reflexões sobre a palavra nos estudos literários, Bakhtín refere-se ao conceito de estética, que apesar de imanente à própria obra de arte, precisa ser definido reciprocamente com outros domínios, na unidade de uma cultura. Ele questiona a primazia da investigação do material na obra de arte, compreensão esta que fatalmente resulta no isolamento das artes umas das outras, baseada na estabilidade do material que, sendo supostamente mais própria para a discussão científica, deve renunciar à pretensão de esgotar a obra de arte (BAKHTÍN, 1993, p. 16-17, 55).

A proposta de Bakhtín pode ser interpretada como o elemento que instaura a constitutiva natureza interdiscursiva da linguagem, ou seja, um permanente diálogo entre os diferentes discursos que configuram uma comunidade, uma cultura, uma sociedade (BRAIT, 1997, p. 98). Seu postulado inalienável do estudo semiótico é a concepção da linguagem enquanto fenômeno social (BAKHTÍN, 1990, p. 259). Este permanente diálogo interdiscursivo constitui a caracterítica conceitual do dialogismo idealizado por Bakhtín, conceito este que transcende os estudos linguísticos e articula-se com os estudos de significação musical, os quais reconhecem que "os signos musicais encontram sua determinação exclusivamente no seu contexto sociocultural" (TARASTI, 2002, p. 8).

A natureza dialógica da linguagem, enquanto propriedade linguística e também propriedade estética, passa a ser reconhecida como eixo de uma teoria geral da cultura, manifesta no conjunto da obra de Bakhtín. Esta reflexão instiga o estudo da estética musical, provocando questionamentos como a capacidade de identificação dos elementos marcantes de relações sociais implícitos em obras musicais e da interdiscursividade presente na música enquanto linguagem, o que favorece a aplicação do conceito de dialogismo também ao 
discurso musical. Não obstante Bakhtín limitar a estética musical ao estudo de uma técnica (BAKHTín, 1993, p. 55), sua concepção social e dialógica da linguagem vai ao encontro de um novo caminho de investigação da semiótica musical: a teoria das tópicas musicais (Musical Topics Theory). Surgida nos anos 80 a partir do trabalho de Leonard Ratner (1980), esta teoria identificou o desenvolvimento histórico de um repertório de figuras musicais características (compreendidos como lugares-comuns) capaz de conferir à música um aspecto significativo sólido e evidente, baseado em seu diálogo com o drama, com a literatura, com a dança e mesmo com fenômenos sociais diversos, enquanto elementos formadores de um complexo cultural integrado pela linguagem, através da associação de expressões musicais que compõe o discurso musical relacionado a esse complexo cultural, que compreende a arte como sua manifestação autêntica, realizada através de materiais múltiplos, mas compreendida como uma estética única, multifacetada, mas sempre interligada e em constante diálogo intertextual.

\section{Sobre a pertinência do estudo semiótico da música}

Desde os primórdios da música instrumental observou-se movimentos de compositores e teóricos buscando uma compreensão significativa da música. 0 ideia da compreensão da música enquanto linguagem já se manifestava em escritos do século XVIII como Der Vollkommene Capellmeister (1739) de Johann Mattheson, que se referia a uma "língua de sons" ("Ton-Sprache") ou "discurso sonoro ("Klang-Rede"). Ainda que estes termos estivessem primariamente associados a uma tradição musical ligada à retórica, observa-se uma sensível aproximação conceitual entre música e linguagem que se consolidava. Já o pensamento sobre a capacidade da música de evocar estados de espírito é muito anterior, tendo sido citada no tratado Melopoiia, do Kantor de São Tomás Seth Calvisius, de 1592. A teoria dos afetos, desenvolvida desde o período barroco a partir de premissas platônicas, buscava sistematizar certas recorrências técnicas associando-as a expressões afetivas ou emocionais, e foi descrita por Joachim Burmeister (Musica poetica, 1606), 
Michael Pretorius (Syntagma musicum, 1619), Marin Mersenne (Harmonie universelle, 1636) Athanasius Kircher (Musurgia universalis, 1650), Christoph Bernhard (Tractatus compositionis augmentatus, ca. 1657) além das obras já citadas de Mattheson e Calvisius, entre tantos outros (UNGER, 2004, p. 99). Muitos compositores baseavam-se nas premissas desta teoria para compor obras musicais, enquanto outros não demonstravam qualquer consideração por seus postulados. Porém, um grande debate sobre a questão só veio a se desenvolver após a consagração dos gêneros exclusivamente instrumentais no fim do século XVII, uma vez que os gêneros vocais que dominaram a música da idade média e do renascimento sempre trouxeram questões de significação, uma vez que tinham no texto literário que era cantado indicativos inalienáveis de suas questões associativo-musicais.

Mesmo durante o século XVIII, com o gradual estabelecimento das formas exclusivamente instrumentais, 280 observou-se ainda uma tendência na escrita instrumental de reproduzir sonoridades pictóricas, buscando "imitar ou simbolizar [na música] ideias específias da poesia e da literatura" (RATNER, 1980, p. 25). Notabilizou-se neste período o surgimento de manifestações prenunciadoras do romantismo que foram identificadas com o termo literário Sturm und Drang (tempestade e ímpeto), que eram caracterizadas por expressões musicais intensas e agitadas, refletindo um caráter tempestuoso, inspirado nas obras de Goethe e Schiller.

Entretanto, com a publicação do livro Vom MusikalischSchönen de Eduard Hanslick (1854), a discussão acerca da significação na música exacerbou-se em polêmicas que envolveram grandes compositores do século XIX, entre estes Johannes Brahms, Franz Liszt e Richard Wagner. Dividiam-se as opiniões entre aqueles que defendiam a música "pura", definida enquanto "formas sonoras em movimento", e aqueles que acreditavam que as associações musicais podiam criar um discurso musical significante, que culminou com o surgimento de uma nova forma musical denominada poema sinfônico, na qual o compositor poderia reproduzir musicalmente um programa literário. Porém estas discussões, mergulhadas nos pressupostos da criação artística do romantismo, apesar de levantarem importantes elementos para o estudo da 
significação musical, apresentaram poucas propostas para uma avaliação consistente das questões que envolvem o significado da música.

Muitos pensadores do século XX abordaram a questão da significação na música reconhecendo sua materialidade, mas pouco se avançou sobre uma sistematização analítica. Luigi Pareyson aborda a problemática da arte mimética, e define o signo artístico como uma figuração do real. Ao falar sobre música, ele questiona:

Quem pode falar a sério de uma música descritiva? Uma peça de música vale pelos seus valores puramente musicais e não por uma capacidade muito problemática de "descrever" a natureza em música. A [Sinfonia] Pastoral de Beethoven é válida enquanto resolve os seus conteúdos na matéria sonora, configurando-a numa forma acabada. Contudo, quem ousaria negar que a natureza está ai presente? É certo que traduzida em valores puramente musicais, mas presente (PAREYSON, 1997, p. 80).

No estudo $O$ problema do conteúdo, do material e da forma na criação literária, Bakhtín apresenta conceitos que, apesar de não serem aplicados pelo próprio autor à estética musical, mostram-se fundamentais na reflexão sobre a semiótica musical, que passa a adotar novos referenciais a partir dos últimos anos do século XX. Esta nova semiótica musical tangencia os postulados linguísticos de Bakhtín em sua essência, pois que a concepção de que o significado efetivo de um discurso verbal só pode se concretizar no seu intercurso sociocultural pressupõe que o discurso musical, que depende diretamente do seu contexto para se realizar enquanto linguagem, constitua também um efetivo sistema de signos integrante de uma cultura.

Paradoxalmente, ao final do mesmo capítulo Bakhtin afirma que o estudo de certas artes deveria limitar-se ao estudo prático de uma única técnica, como é o caso da estética da música, cuja análise não teria nada a dizer além da própria definição geral de sua originalidade. Porém, logo em seguida, ele conclui que é possível imaginar um tipo particular de interpretação filosófico-subjetiva da obra musical, mas que não 
se propõe a esboçar o método de análise composicional do material (BAKHTÍN, 1993, p. 46).

No primeiro capítulo do mesmo estudo, Bakhtín faz referência à música para tratar da determinação cognitiva, definindo o conteúdo como um momento indispensável no objeto artístico. Partindo desta premissa, afirma que:

(...) estar livre da determinação do conceito absolutamente não equivale a estar livre do conteúdo (...) A música é desprovida de determinação objetal e de diferenciação cognitiva, mas ela tem muito conteúdo: sua forma nos conduz à sonoridade acústica, e absolutamente não a um vazio axiológico; aqui o conteúdo, em sua base, é ético (poder-se-ia falar também de um abstrativismo livre, não determinado, da tensão ética recoberta pela forma musical). Uma música sem conteúdo, enquanto material organizado, seria nada mais que um estimulante físico do estado psicofisiológico do prazer. (BAKHTÍN, 1993, p. 21).

Para que se possa compreender as questões de semiótica musical no contexto da proposta da teoria cultural de Bakhtín deve-se, portanto, transcender o limite imposto por seu próprio trabalho quando se refere à música. Distanciandose da efervescência das discussões sociais do início do século XX que, de certo ponto de vista, integravam uma militância política de alcance mundial, é possível trabalhar os conceitos de Bakhtín através de um novo caminho de investigação da semiótica musical, que parte do pressuposto de que a estética de uma arte é a estética das outras: somente o material é que se diferencia.

\section{Sobre o estudo dos estilos, tipos e tópicas musicais}

Considerando-se a ideia de Bakhtin de que a totalidade das significações culturais constitui um sistema de signos, e que a música é elemento evidentemente integrante do conceito de cultura, pode-se afirmar que a música, compreendida enquanto linguagem, apresenta uma dimensão dialógica e social, partindo dos pressupostos de sua teoria.

Dentre as abordagens para o problema das relações semânticas dos signos musicais a teoria das tópicas musicais 
(Musical Topics Theory) tem se destacado como uma importante contribuição nesse campo, sendo adotada por diversos pesquisadores que têm ampliado consideravelmente seu escopo.

Leonard Ratner em Classic Music - Expression, Form and Style (RATNER, 1980, p. 9), estuda o desenvolvimento histórico, a partir do século XVIII, de um repertório de figuras características que, em função do contato com o drama, a literatura, a dança e mesmo com fenômenos sociais, consolidaram-se como associações musicais de expressões, afetos ou de caráter pitoresco e se tornaram elementos do discurso musical - as tópicas musicais. Ratner divide as tópicas em três categorias: passos de dança, estilos e expressões pictóricas. Os principais passos de dança se firmaram no período barroco: o minueto, a gavota, a giga, o passepied, a bourrée, as contradanças, entre outros.

O estudo dos passos de dança que se desenvolveram nos períodos musicais do barroco e do classicismo mostra-se como um dos primeiros caminhos para uma compreensão social da música: todo o passo de dança é ligado à classe social que a pratica: enquanto o minueto derivava do estilo das cortes, as contradanças relacionavam-se com as tradições populares do baixo estilo. A analogia entre passos de dança e classes sociais foi, provavelmente, um dos primeiros indicadores de uma visão sociológica da música e tornou-se a porta de entrada para um amplo universo interpretativo. Neste contexto, a música folclórica representa também um importante elemento para o estudo social da música, enquanto uma manifestação remanescente de uma cultura "pré-classes" que perdura em uma sociedade cuja cultura torna-se cada vez mais cosmopolita.

A segunda categoria de tópicas, os "estilos", inclui, entre outros, a música militar e a música de caça, a abertura em estilo francês, os estilos cantabile, brilhante e alla turca, o estilo estrito (ou contrapontístico), que são referências eminentemente musicais; além destes, há os estilos de referência literária, tais como Sturm und Drang (tempestade e ímpeto) e Empfindsamkeit (sensibilidade). Nesta categoria, as relações sociais ficam ainda mais evidentes: as marchas 
cerimoniais e a música de caça fazem parte de um universo cultural radicalmente segregado das classes servis anteriores à revolução francesa. A música militar, que em linhas gerais refere-se muito mais às patentes de capitania, possui uma latente dubiedade, pois um exército é sempre formado majoritariamente por soldados, e não por capitães. Já os conceitos literários cunhados por Goethe e Schiller transformam-se em elementos de vasta investigação estética sob o prisma social.

A terceira categoria de tópicas de acordo com Ratner compreende a expressão musical baseada no pictorialismo, ou seja, a imitação de sons existentes na natureza com intenção descritiva, tais como a tópica pastoral. É interessante observar que, no período barroco, já existiam os estilos de passos de dança, mas eles normalmente eram a única tópica presente em determinado movimento musical, como se dá com cada um dos movimentos de uma suíte ${ }^{2}$. Já a música do classicismo vienense sistematizou o emprego sucessivo de diferentes tópicas dentro do mesmo movimento musical, processo que coincidiu com a estabilização da forma sonata, em que o princípio de contraste entre o tema principal e o secundário, inicialmente de caráter essencialmente harmônico (tema principal na tônica/tema secundário na dominante), passou pouco a pouco a privilegiar a utilização de diferentes tópicas dentro da mesma música (ou movimento), com finalidade expressiva. Gradualmente, a sucessão de tópicas transformou-se em combinações entre elas, denominada tropo, e as referências tópicas tornaram-se cada vez mais numerosas, com o surgimento de novas poéticas e o intercâmbio entre as diferentes manifestações artísticas.

Um dos principais estudiosos das tópicas musicais que deu prosseguimento à investigação da linha proposta por Ratner foi Raymond Monelle. Em seu livro The musical topic

\footnotetext{
2 Ainda que existam exceções, como em algumas toccatas e capriccios onde há alternância de estilos ou expressões afetivas, observa-se como característica da música barroca a unidade de estilo ou de tópica no âmbito de movimentos ou seções de obras, ainda que haja um formidável contraste entre estes movimentos ou seções de uma única obra.
} 
(2006) propõe a revisão das três categorias de Ratner em termos semióticos (MONELLE, 2006, p. 4). As tópicas que constituem passos de dança apresentam significantes e significados simples - o ritmo de uma sarabanda inicialmente significa "sarabanda" - ou seja, sua qualidade ou característica constitui um ícone primário. Essa visão se aplica quando a dança a que a tópica se refere é contemporânea à sua utilização como tópica musical. É, porém, muito comum encontrar tópicas anacrônicas; o emprego, por exemplo, de uma tópica que se refere a um passo de dança que já não é praticado configura uma atitude nostálgica, como um minueto escrito no fim do século XIX ou XX. Outras tópicas limitaram-se a períodos mais curtos, constituindo puros "modismos", como o alla turca, presente na ópera O Rapto do Serralho e na Sonata KV 331 de Mozart, que foram um reflexo da moda orientalista na cidade de Viena do fim do século XVIII. Por outro lado, existem tópicas que constituem verdadeiros gêneros musicais e culturais, especialmente aqueles que são referenciados na literatura, cujos significantes são multifacetados, e os significados, complexos. Um exemplo típico é o da tópica pastoral: o timbre da flauta e do oboé, o ritmo da siciliana e os pedais de musette são significantes de uma atividade pastoril idealizada, relacionada à tranquilidade da vida no campo e a paisagens amenas - é o locus amonus da antiguidade clássica. Entretanto, também aqui a tópica é anacrônica, para não dizer inteiramente imaginária, uma vez que, desde a antiguidade, a vida pastoril na realidade material tem pouca ou nenhuma relação com o locus amœnus cantado pelos poetas de sucessivos séculos, em diferentes regiões. Portanto, esses significantes musicais guardam uma relação de contiguidade, ou seja, um símbolo, que constitui uma associação terciária, transcendendo a qualidade tipológica e a similaridade metafórica para constituir uma convenção metonímica. Utilizando a nomenclatura de Peirce (MONELLE, 2006, p. 27), identifica-se o ícone primário, cuja característica ou qualidade constitui sua identidade; o índex secundário, que supõe uma relação de similaridade; e o símbolo, associado através de uma relação de convenção, seja por dedução de uma experiência prévia ou de um processo de causa e efeito. 
Robert Hatten, um dos mais importantes estudiosos da significação musical da atualidade, compreende na análise tópica uma concepção tanto estruturalista, na reconstrução historicamente informada de tipos estilísticos, como também hermenêutica, na interpretação da estrutura pela qual um compositor individualiza e particulariza o emprego destes tipos, que adquirem significados expressivos únicos. Seu estudo se direciona na maneira pela qual é possível identificar significados na música, e não meramente quais seriam os significados de uma determinada música (HATTEN, 2004, p. 21).

Enfim, a tópica musical, a despeito de ser constituída por materiais puramente musicais (conforme observou Pareyson), tem a propriedade de localizar a música na história e na cultura, e pode revelar também suas muitas contradições. Por exemplo, a sociedade monarquista europeia do século XVIII transmitiu suas características culturais à música de seu tempo.

286 A música de Haydn e Mozart pertencia eminentemente à nobreza: as danças (minueto, gavota etc.), a pompa das marchas, a música de caça e o ideal pastoral eram tópicas musicais fundamentais na obra desses compositores, não obstante a presença recorrente de tópicas provenientes do "baixo estilo", como as contradanças de caráter popular e os Ländler ${ }^{3}$, que se tornaram cada vez mais presentes na música do romantismo, em especial nas sinfonias de Gustav Mahler. A recorrência da música do baixo estilo em composição com a linguagem refinada do sentimentalismo romântico revela uma tendência que pode ser relacionada ao conceito de carnavalização proposto por Bakhtín, e a reunião das expressões opostas pode ser associada ao conceito de heteroglossia, ou seja, a utilização de diferentes linguagens ou padrões de gêneros no discurso musical, como se na música príncipes e mendigos intercambiassem seus papéis, representados pelo emprego de estilos e tópicas.

3 Dança popular típica do sul da Alemanha, Suíça, Áustria e Eslovênia, usualmente em compasso ternário $(3 / 4)$ e andamento rápido, difundida e praticada amplamente até o fim do século XIX. 
Considerando-se, portanto, este caráter dialógico verificado na investigação das tópicas musicais, observa-se uma correspondência entre o seu método e a concepção bakhtiniana de que cada fenômeno da cultura ocupa uma posição substancial em relação à realidade preexistente de outras atitudes culturais, integrando, portanto, uma unidade cultural prescrita.

\section{Sobre as particularidades da investigação musicológica no contexto das artes}

Enquanto a teoria literária procura compreender a transcendência das relações entre significantes e significados na literatura, desdobrando o estudo literário e compreendendo suas relações com a sociedade, a música ainda dá os primeiros passos no entendimento de seus signos, levantando questões filosóficas acerca de sua dimensão semiótica. Porém, a compreensão proposta por Bakhtín de que os signos só podem se constituir como sistema a partir de alguma forma de organização social (BAKHTIN, 1979, p. 30) abre caminho para uma cientificidade cada vez mais ampla da investigação das tópicas musicais. 0 próprio conceito de lugar-comum traz implicitamente um pressuposto sociológico - comum é aquilo que é característico de uma comunidade. Por esta mesma razão torna-se evidente que a música, a despeito da dimensão universal de sua linguagem, pode ser identificada como pertencente a uma determinada cultura, a uma determinada região ou grupo - está inserida na totalidade de uma cultura. A música da Rússia não fala um idioma diferente da música brasileira ou italiana, mas apresenta signos característicos e recorrentes da música que é produzida naquela sociedade, e é possível realizar um estudo semiótico dos elementos presentes nesta música e associa-los, em maior ou menor grau, a fatos históricos e fenômenos culturais sucedidos naquela comunidade. Dessa forma, um dos caminhos para a aplicação da teoria cultural de Bakhtín na semiótica musical é a análise dos signos tipológicos musicais presentes em diferentes graus de evidência em qualquer manifestação musical. A partir deste 
pressuposto, pode-se aprofundar a reflexão sobre a ambivalência do signo, perfeitamente aplicável ao signo musical, que pode refletir ou refratar uma realidade, ou seja, pode apreendê-la com fidelidade ou pode distorcê-la (KONDER, 2012, p. 115). Dmitri Chostakóvitch, compositor soviético expoente da produção musical do período socialista, declarou em uma entrevista ao New York Times em 1931: "não há música sem ideologia, e os compositores sempre manifestaram em sua música, de forma consciente ou inconsciente, suas concepções políticas" (LEE, 1931). O estudo da manifestação ideológica na música pode ser associado à proposição de Bakhtín de que "tudo o que é ideológico é um signo. Sem signo não existe ideologia" (BAKHTIN, 1979, p. 17).

Por outro lado, é importante ressaltar que esta comparação entre o estudo de semiótica musical e a teoria literária não pretende simplesmente evidenciar uma diferença no grau de desenvolvimento do estudo dos signos na obra de

288 arte, onde claramente a teoria literária, em grande medida devido aos estudos de Bakhtín, encontra-se avançada em relação à musicologia. Esta reflexão comparativa pretende muito mais descobrir caminhos para que os avanços dos estudos literários possam auxiliar no avanço dos estudos musicológicos, não ignorando o fato de que muitos aspectos da investigação musical podem revelar caminhos pouco explorados da teoria literária.

Neste sentido é possível apresentar neste estudo pelo menos um elemento imanente da linguagem musical que pode servir como paradigma para os estudos literários: o domínio da imaginação na indeterminação da linguagem. A utilização da figura da metáfora na literatura é estudada de forma intensa pelos estudos literários, que em muitos momentos mostram-se focados na busca de uma determinação para um fenômeno linguístico que pretende exatamente ser seu oposto, ou seja, pretende a indeterminação, a fim de que o espaço indeterminado da linguagem seja preenchido pela imaginação do leitor. Quando o autor diz que um objeto é outro, sendo que no domínio da materialidade ou objetividade não o é, ou mesmo na comparação, quando diz que um objeto é como outro (sem realmente o ser), o autor busca com este recurso indeterminar o objeto referido, criando o espaço para a 
imaginação do leitor apropriar-se da imagem do objeto, transformando-a, perfazendo sua realização no campo ético e sua relação com o cognitivo. Portanto, o quanto menos marcada (ou seja, determinada) for a comparação, tanto mais espaço haverá para a imaginação. A partir desta afirmação pode-se concluir que o problema da (in)determinação da linguagem é uma das mais importantes questões do estudo da semiótica musical, pois a análise dos signos musicais sempre passará pelo nível de marcação, ou seja, pelo grau de determinação de seu significado, e uma das conclusões que se chegará na análise musical será que muitos signos musicais apresentam marcação parcial ou limitada, ou seja, um grau reduzido de determinação, proporcionando um enorme espaço para a imaginação e decorrente envolvimento do ouvinte. Portanto, é possível dizer que o emprego da metáfora na literatura constitui um mecanismo de indeterminação que resulta no favorecimento ao domínio da imaginação do leitor, ou seja, aproxima a linguagem literária da linguagem musical, que por natureza apresenta signos de menor grau de determinação. Esta concepção da metáfora é evidentemente dialógica, e enfatiza a compreensão bakhtiniana de que a arte encerra uma dimensão discursiva e sua apreciação constitui um diálogo sensível com o apreciador.

O exemplo da metáfora enquanto figura de linguagem comum à música e à literatura constitui apenas uma possibilidade, em meio a inúmeras outras, de intercâmbio metodológico entre a teoria literária e a musicologia, onde os estudos de Bakhtín tornam-se referências essenciais, ainda que o próprio autor não tenha desenvolvido pesquisas aprofundadas no campo específico da estética musical.

A música, que caminha na busca pela compreensão de suas relações semióticas, deve ainda aprender da teoria cultural de Bakhtín que o grande trabalho do artista com o material, seja este composto por palavras ou sons, tem sempre por objetivo final a sua superação imanente, ou seja, seu aperfeiçoamento expressivo que conduzirá à sua própria superação. Portanto, a investigação das relações semióticas na música não pretende esgotar a expressão da obra de arte, mas sim aproximar-se da dimensão transcendente de sua existência. 


\section{Referências bibliográficas}

BAKHTÍN, Mikhaíl Mikhaílovich. M. The Dialogic Imagination - Four Essays by M.M. Bakhtín. Edited by Michael Holquist. Translated by Caryl Emerson and Michael Holquist. Austin: University of Texas Press, 1990. [1 ${ }^{\mathrm{a}}$ ed. 1981].

Marxismo e Filosofia da Linguagem. Trad. Michel Lahud e Iara Frateschi Vieira. São Paulo: Hucitec, 1979.

Questões de Literatura e Estética. Trad. Aurora F. Bernardini, José Pereira Júnior, Augusto Góes Júnior, Helena Spryndis Nazário e Homero Freitas de Andrade. 3a ed. São Paulo: Editora UNESP, 1993. (1aa edição: Khudojestvennaia Literatura: Moscou, 1975).

BAKHTÍN, Mikhaíl Mikhaílovich; MEDVEDEV, Pavel Nikolaevitch. The Formal Method in Literary Scholarship. London: The Johns Hopkins University Press, 1991. [1ํㅡㄹ ed. 1978].

290 BRAIT, Beth (org.) Bakhtín, dialogismo e construção do sentido. Campinas: Editora da Unicamp, 1997.

DAHLHAUS, Carl. Musikästhetik. Köln: Musikverlag Hans Gerig, 1967.

HANSLICK, Eduard. Do Belo Musical. Tradução de Artur Morão. Lisboa: Edições 70, [19--] [1ํㅡ ed. alemã 1854].

HATTEN, Robert S. Interpreting Musical Gestures, Topics and Tropes: Mozart, Beethoven, Schubert. Bloomington: Indiana University Press, 2004.

KONDER, Leandro. A questão da ideologia. São Paulo: Companhia das Letras, 2002.

LEE, Rose. Dimitri Szostakovitch - Young Russian Composer Tells of Linking Politics With Creative Work. New York Times, New York, 20 Dec. 1931

MONELLE, Raymond. The Musical Topic. Hunt, Military and Pastoral. Bloomington: Indiana University Press, 2006

PAREYSON, Luigi. Os problemas da estética. Tradução de Maria Helena Nery Garcez. 3a ed. São Paulo: Martins Fontes, 1997 [1 ${ }^{\underline{a}}$ ed. italiana 1966].

RATNER, Leonard. Classic Music - Expression, Form and Style. London: Collier Macmillan, 1980. 
TARASTI, Eero. Signs of music: a guide to musical semiotics. Berlin: Mouton de Gruyter, 2002.

UNGER, Hans-Heinrich. Die Beziehungen zwischen Musik und Rhetorik im 16.-18. Jahrhundert. Hildesheim: Georg Olms Verlag, 2004. 